\title{
Discussion: Educating engineers in the workplace
}

Barry G. Clarke PhD, CEng, Eur Ing, FICE, FGS

Professor of Civil Engineering Geotechnics, Institute of Resilient

Infrastructure, School of Civil Engineering, University of Leeds, UK
John Anderson MBA, PhD, CEng, FICE, FIMMM, FGS

Consulting civil engineer and expert witness, independent and self-employed, Chester, UK

\section{Contribution by John Anderson}

With reference to the paper by Clarke published in the 2011 edition (Clarke, 2011), the contributor regrets that there is no mention of any kind of construction industry occupational health and safety at work in the paper. There has been an ongoing dialogue/debate between the ICE Health and Safety Panels and Boards and the JBM for at least the past 30 years on whether the JBM guidelines on occupational health and safety should be compulsory within any ICE-accredited first degree course. When talking about 'education in the workplace' the first task is surely the need for both education and training in the prevention of accidents and case of ill health. This will not happen without pre-planning and the deployment of expertise. The matter has been written about for years (Anderson, 1992, 1999, 2002, 2010, 2011), and, yes, the contributor is an enthusiast - and for very good reasons - a hatred of death, injury and cases of ill health on any construction site.

\section{Author's reply}

The contributor is more than suitably qualified to emphasise the need for graduates to be educated on the importance of health and safety and the need to be trained in the workplace. Therefore his comments are very welcome and informative.

However, it was not the intention of the paper to be prescriptive but rather to describe the process by which a graduate can become professionally qualified. The aim is to achieve a number of learning outcomes at the appropriate level so that they complete the educational base to become professionally qualified. The outcomes will depend on the opportunities there are for learning and the outcomes needed to complete the educational base; that is, the gap between the knowledge and understanding gained through formal education and that required by the UK Specification.

The JBM reinforces the health and safety message on every one of their visits to universities and therefore the assumption is that graduates will have knowledge of health and safety matters. The intention is that they will develop a culture of health and safety awareness. Universities are not the best places to learn about and practise occupational health and safety. It is appropriate to develop those skills in the workplace where they have to address these issues on a daily basis; not in some hypothetical situation but in a real situation. Therefore it would be entirely appropriate for a graduate to develop a learning plan that contained an element of occupational health and safety education and training to show that they had achieved the appropriate learning outcome. It is up to the graduate working with the mentor to decide on what they have to cover as part of the workplace education.

It is worth noting that the following items are the only learning outcomes that specifically refer to health and safety.

(a) Awareness of the framework of relevant legal requirements governing engineering activities, including personnel, health, safety, and risk (including environmental risk) issues.

(b) Investigate and define a problem and identify constraints including environmental and sustainability limitations, health and safety and risk assessment issues.

Hence graduates are expected to have an awareness of the legal framework and the issues that have to be taken into account in design but not of occupational health and safety. This is embedded in other learning outcomes such as understanding of appropriate codes of practice and industry standards.

\section{REFERENCES}

Anderson JM (1992) Managing safety in construction. Proceedings of the Institution of Civil Engineers - Civil Engineering 92(3): 127-132.

Anderson JM (1999) Health and safety - the missing ingredient. Proceedings of the Institution of Civil Engineers - Civil Engineering 132(1): 41-42.

Anderson JM (2002) Health and safety - time for a new approach. Proceedings of the Institution of Civil Engineers Municipal Engineer 150(4): 150-157.

Anderson JM (2010) Regulations to improve construction health and safety. Proceedings of the Institution of Civil Engineers - Management, Procurement and Law 163(3): 97-100. 
Anderson JM (2011) A strategy for clients for procurement of good health and safety. Proceedings of the Institution of Civil Engineers - Management, Procurement and Law 164(2): 59-60.
Clarke (2011) Educating engineers in the workplace. Proceedings of the Institution of Civil Engineers Management, Procurement and Law 164(2): 89-98. 